\title{
CANADIAN CITIES IN TRANSITION: NEW SOURCES OF URBAN DIFFERENCE
}

\author{
Larry S. Bourne \\ Department of Geography, University of Toronto, \\ Toronto ON M5S 3G3, Canada \\ e-mail: Bourne@geog.utoronto.ca
}

\begin{abstract}
Cities, increasingly, are the principal arenas in which global, national and local forces intersect. Canadian cities are no exception. Those cities are currently undergoing a series of profound and irreversible transitions as a result of external forces originating from different sources and operating at different spatial scales. Specifically, this paper argues that Canadian cities are being transformed in a markedly uneven fashion through the intersection of changes in national and regional economies, the continued demographic transition, and shifts in government policy on the one hand, and through increased levels and new sources of immigration, and the globalization of capital and trade flows, on the other hand. These shifts, in turn, are producing new patterns of external dependence, a more fragmented urban system, and continued metropolitan concentration. They are also leading to increased sociocultural differences, with intense cultural diversity in some cities juxtaposed with homogeneity in other cities, and to new sets of urban winners and losers. In effect, these transitions are creating new sources of difference - new divides - among and within the country's urban centres, augmenting or replacing the traditional divides based on city-size, location in the heartland or periphery, and local economic base.
\end{abstract}

Key words: urban differences, diversity, globalization, Canadian cities

\section{SETTING THE STAGE}

Cities are widely viewed as the principal arenas in which global, national and local forces intersect. They are the settings where the synergies, opportunities and tensions generated by these forces operating in combination are mediated, and the resulting conflicts are resolved, accommodated or magnified. They are also where the outcomes become more visible politically. As a consequence, cities are now said to matter politically, even in Canada (Bradford, 2002). 
Of course, cities have always served this pivotal role. Yet, there is general agreement that with continued urban growth and metropolitan concentration, fuelled by the forces of globalization, the intensity of the impacts of external forces has increased accordingly. Cities are being transformed in multiple and seemingly irreversible ways through the effects of external forces, including globalization, but more emphatically through the intersection of these external forces with national conditions and local factors.

This paper argues that Canadian cities are not immune to this mix of forces. Indeed, they offer an exceptionally rich example of the speed, scale and complexity of change and the importance of external forces. Specifically, the paper examines the proposition that Canadian cities are being transformed but in a markedly uneven fashion through the intersection of changes in the economy, both national and regional, in the country's demographic structure, and through shifts in government policies and practices. At the same time, changes attributable to global forces such as economic competition, trade liberalization and capital flows, and immigration, have been superimposed on the national landscape and on Canadian cities. The hypothesis is that the combination - the intersection - of these trends has reorganized the urban system and created new divides and sources of "difference" among and within Canadian cities.

The first part of the paper examines changes in both national and global forces as the context of urban growth and change. The second section documents the uneven impacts of these forces on the urban system and then on individual cities. The third section argues that these impacts, in turn, are creating new sources and new kinds of differences among cities that have augmented, and in some instances replaced, traditional sources of differences. The concluding section explores some of the implications of these emerging differences for the future of cities and the quality of life they provide.

\section{CONTEXT: EXTERNAL SOURCES OF CHANGE}

What are the underlying factors that have driven these changes? How have they affected cities and city-regions? This section examines four sets of trends that have reshaped the urban system and the context in which it has evolved: 1) the restructuring of the economy; 2) shifts in trade flows; 3 ) the demographic transition and immigration; and 4) the changing role of governments. All of these are closely related but each has its own dynamic, and its own distinctive geography. The following analysis is a brief summary that builds on a series of recent papers that explore the empirical dimensions of the Canadian urban system in considerable detail (Simmons and McCann, 2000; Bourne, 2002; Bourne and Simmons, 2003; Simmons and Bourne, 2003).

The Economy: The first set of trends involves the ongoing restructuring of the national economy, set within a changing global context of transnational integration and intense economic competition. These trends are similar to those prevailing in most western countries and are generally well documented in the international literature (Geyer, 2002; Champion and Hugo, 2003). But in Canada they also have a peculiar, if not unique, historical and 
geographical base. The national economy has continued to shift in its sectoral composition from natural resources and basic manufacturing to services, both public and private. From 1981 to 2001 the country added 3.6 million jobs, of which over $80 \%$ have been created within the services sector. In a country spread over a vast continent, with a high degree of regional economic specialization, this sectoral transformation has also shifted the spatial distribution of economic growth, and thus the geography of urbanization. The fastest rates of growth, until recently, have been in high-order services in business and high-tech information sectors, as well as in the health and educational fields, all of which are overwhelmingly concentrated in the larger metropolitan areas or their immediate surroundings.

It seems that there is a new premium attached to agglomeration economies and location, and specifically to a location in or near a large metropolitan area. Despite the rhetoric that the IT and communications revolution would lead to the elimination of distance as a constraint on location decisions, the opposite seems to have happened. The effect of distance has been redefined but not eliminated. Space and place have become more not less important. Even high-tech and communication firms, which in theory are both wireless and footloose, as well as those activities most commonly associated with the new cultural sectors of the economy, are heavily concentrated in metropolitan regions, especially the larger places - the so-called global cities (Beaverstock et al, 2000; Marcuse and van Kempen, 2000). These are also places with strong international linkages, thick labour markets and high levels of employment in social and producer services. The periphery has not as yet benefited from the borderless world assumed in the knowledge economy (Polese and Shearmur 2002).

Trade Flows: The rate of sectoral economic change in Canada has been accelerated by a series of trade agreements, with the Free Trade Agreement (1989) and NAFTA (1994) as the benchmarks. International trade flows have increased dramatically during the 1990s and now exceed the flows of commodities among the country's major regions. Trade liberalization has not only opened the border wider to imported goods (and to some services) it has changed the geography of the destinations of imports and the origins of exports. This, in turn, has augmented an already uneven pattern of urban growth. That pattern is dependent not only on the goods produced but on the emerging networks of linkages between urban places and export markets. In the Canadian case this openness reflects a broadening of the country's traditional economic dependency on external markets, and thus the increasing degree of vulnerability to the actions of foreign governments, multi-national firms and organizations, and international regulatory agencies. Since most of this increased trade has been with the US, the trend can be seen not as a result of globalization per se, but rather the outcome of the continental integration of the Canadian economy within an expanding North American market that is also overwhelmingly dominated by the United States.

One of the longer-term consequences of this shift in trade flows, and the increasing importance of international links compared to interregional links, may be political. It may, for example, undermine the implicit social contract that binds regions in Canada together as a nation state (Courchene and Telmer, 1998). That social contract incorporates, among other inherited norms, a trade-off between the east-west flow of goods and services between the core and the periphery in exchange for equalization payments and the transfer of fiscal 
resources from richer to poorer regions. Why would richer regions continue to support such transfers if the markets provided by the peripheral regions are of diminishing importance to the national economy relative to the size of international markets.

Equally problematic, there are no exchange mechanisms within the emerging North American economic zone to compensate for differences in economic performance and standard of living. Unlike the European Community, there are no effective institutions or policies for equalization, or for the trans-national transfer of fiscal resources, and certainly not the cross-border interregional transfer of resources, from richer to poorer regions. Indeed, the reverse is likely to be the case.

The Demographic Transition and Immigration: Equally dramatic transformations have taken place in the country's demography. This, in turn, is reflected in shifts in the relative importance of the different components of national and urban population growth, especially the increasing prominence of immigration. First, the demographic transition in Canada has, by any standard, been extremely sharp. The initial post-war baby-boom (19471965) produced the highest fertility levels and the largest single population age cohort in the country's history. This was followed by an equally sharp decline in fertility, and thus in rates of natural increase (the baby-bust), from the 1970s onward. Fertility levels are now at historically low levels, and are more-or-less uniform across the country (except for aboriginal communities). One obvious result of this decline is a rapidly aging population.

Second, the increasing scale of immigration flows since the 1980s, both in absolute terms and relative to rates of natural increase, has altered the mix and the geography of growth. Immigration now averages around 225,000 persons per annum, and accounts for over $50 \%$ of national population growth and over $70 \%$ of labour force growth. The ethnocultural composition of those flows has also shifted. In the 1960s almost $80 \%$ of immigrants came from Europe and the US; now over $80 \%$ come from non-traditional sources, largely in Asia, Africa and the Caribbean. Moreover, those flows are geographically uneven, and are largely focused on a few metropolitan areas. Between $70 \%$ and $80 \%$ of immigrants are destined for the three largest metropolitan areas, with nearly $50 \%$ going to the Toronto region alone. This has changed the face and feel of these cities almost beyond recognition. For most of the rest of the country, in contrast, the level of immigration is relatively low, or non-existent.

Third, interregional population flows have been relatively constant. The absolute size of flows of domestic migrants among regions within the country has remained more or less stable over the last two decades, and thus has declined in proportional terms as the country's population has expanded. In other words, domestic migration has declined as a factor accounting for differences in regional and urban population growth rates, and as a means of adjusting the supply of labour to the market demand for workers and skills. Net domestic (e.g. inter-provincial) migration currently averages roughly 50,000 persons per year; while immigration adds over 175,000 people (net of emigration).

The Role of Government: The actions of governments, even in those countries - such as Canada - without explicit national urban policies, have a significant impact on how the urban system evolves and on the character of individual cities. They can also be the prin- 
cipal architects of urban convergence or increasing difference. Although national governments may have lost considerable autonomy in macro-economic affairs, they still control, or at least influence, trans-national movements of goods, labour and people, and to a lesser extent, capital.

The intersections between public policies can be substantial. For example, two recent policy decisions by the federal government in Canada - with respect to furthering trade liberalization and accelerated levels of immigration - have had dramatic and largely unanticipated effects on the structure and organization of the national economy and on the social character of cities. These effects have been intensified by the unevenness of the geography of the processes involved, especially among regions and within cities.

It can be argued that the country's principal population policy, albeit an implicit policy, mirrors decisions and practices on immigration (Ley and Hiebert, 2001). The stated objectives of the latter policy are to enhance labour force skills, to increase the size of the domestic market, and to avoid population decline in the future. But it is also transforming the country's social fabric, most dramatically in the cities receiving the majority of the immigrants. It can also be argued that immigration policy, because of the localized geography of its outcomes, is the country's implicit urban policy (Bourne and Simmons 2003). That policy implies, given the highly concentrated destinations of the immigrants, that Canada's larger urban regions - notably Toronto and Vancouver - are not large enough.

Summary: The above trends, for the most part, are not entirely new; nor are they specific to Canada or to Canadian cities. What is new is the emergence of new intersections in space and time between external and domestic forces, measured in terms of both the origins and the outcomes of the trends. Two examples of these intersections will suffice here. One described above relates to population growth and change. In Canada, as in most other countries, there have been periods of low fertility levels in the past (e.g. 1930s), and periods of high immigration levels (e.g. 1900-1920; 1950s). But these two conditions - low fertility and high immigration - have never prevailed at the same time, as they do now, and not in the same spatial configuration. As the geographies of natural increase (fertility) and immigration differ markedly, with rates of natural increase low and relatively even, in contrast with immigration which is relatively high and spatially concentrated, their imprints on urban growth and population characteristics are therefore substantially different.

The second example of the intersection premise is the coincidence in time of the increasing liberalization of trade, and thus a larger role for foreign markets and agents in the geography of economic development, and the extensive decentralization (or downloading) of fiscal responsibilities from national to lower (provincial and local) levels of government. This downloading has not, however, been accompanied by a corresponding redistribution of revenues. To the extent that increased trade and immigration introduce greater uncertainty into national equations for urban growth, recent federal and provincial government actions, especially with respect to downloading, have at the same time reduced the ability of urban governments to adapt to that uncertainty. 


\section{URBAN OUTCOMES}

The combined outcomes of the above factors, and especially their intersections, have reorganized the urban system in Canada and transformed the social and economic characteristics of individual cities and city regions in that system. The urban system is defined here as including 139 urban places with over 10,000 population - 27 census metropolitan areas (CMAs) and 122 census agglomerations (CAs).

Because of low fertility levels, overall population growth rates have slowed, although they are still relatively high by western European standards. As a result, a much higher proportion of urban areas - both census metropolitan areas (CMAs) and census agglomerations (CAs) - actually declined in population over the last census period. Among smaller urban centers some 44\% declined in population between 1996 and 2001, including several of the smaller metropolitan areas. For that part of the country outside of the urban system that is, outside of the 139 CMAs and CAs - population declined by $0.4 \%$ during the last census period (Table 1).

Table 1: The variability of urban growth in Cnada, by city size and relative location, 19962001.

\begin{tabular}{lcc}
\hline Location/Region & $\begin{array}{c}\text { Number of Places } \\
\mathrm{N}=\end{array}$ & $\begin{array}{c}\text { Growth Rate } \\
1996-2001\end{array}$ \\
\hline $\begin{array}{l}\text { By City Size: } \\
\text { All urban areas (CMAs and CAs) } \\
\text { (over 10,000 population) }\end{array}$ & 139 & $5.2 \%$ \\
$\begin{array}{l}\text { Metropolitan Areas (CMAs) } \\
\text { (over 100,000 population) }\end{array}$ & 27 & $6.2 \%$ \\
$\begin{array}{l}\text { Small urban areas only } \\
\text { (10,000 to 100,000) }\end{array}$ & 112 & $1.5 \%$ \\
$\begin{array}{l}\text { Non-urban areas (non-CMA/CA) } \\
\text { National growth rate }\end{array}$ & 3800 & $-0.4 \%$ \\
& & \\
By degree of metropolitan linkages and influence for all non-CMA/CA places: location \\
and accessibility with respect to CMAs/CAs:
\end{tabular}

Source: Statistics Canada, MIZ files, and author's calculations.

Within the non-CMA/CA part of the country, proximity to a metropolitan area, or a large urban region, also seems to matter more under these conditions. A recent study of all communities located outside of the country's urban system showed that growth rates declined systematically the further away those communities were (Bourne and Simmons 2003). Using 
commuting to work as a composite index, places that were close enough to send a significant number of commuters to a larger urban area grew most rapidly. Those communities, in contrast, that are so isolated that commuting to a larger place was impossible actually declined in population. In this case, proximity means not only access to employment alternatives in a different but nearby labour market, but also access to specialized services, such as health and educational facilities, that are generally not available in smaller communities. Ironically, the demand for those services is increasing most rapidly precisely in those areas least able to afford or sustain them.

At the same time, urban growth has become more uneven across the country. Places that are growing rapidly, which tend to be those attracting immigrants, are juxtaposed with those undergoing serious decline, often within the same region. The coefficient of variation, which measures the variability of growth over the urban system, was the highest ever recorded during the last census period. Population decline was most common in the eastern regions - in Atlantic Canada and Quebec - and among the more isolated resource-base communities in the north. But urban decline is also now a prominent feature in parts of the traditional core region of southern Ontario. It appears that the settlement frontier in Canada has been retreating, with people and economic activity migrating southward.

In contrast, the larger metropolitan regions have continued to grow, driven primarily by immigration. As a result, the level of metropolitan concentration has increased. Almost 85 percent of all growth has taken place within five of the larger metropolitan regions Toronto, Montreal, Vancouver, Ottawa-Gatineau, and the Calgary-Edmonton corridor (Table 2).

Table 2: Emerging urban regions in Canada, 2001

\begin{tabular}{llccc}
\hline Rank & Region & $\begin{array}{c}\text { Population } \\
2001\end{array}$ & $\begin{array}{c}\text { Growth } \\
\text { Rate }\end{array}$ & $\begin{array}{c}\text { 1996-01 } \\
\text { Canada }\end{array}$ \\
\hline 1 & Golden Horseshoe & $6,700,000$ & $7.4 \%$ & 22.3 \\
2 & Montreal Region & $3,500,000$ & $2.9 \%$ & 11.7 \\
3 & Vancouver - Victoria & $2,700,000$ & $7.3 \%$ & 9.0 \\
4 & Edmonton - Calgary & $2,150,000$ & $12.3 \%$ & 7.2 \\
5 & Ottawa - Gatineau & $1,100,000$ & $5.9 \%$ & 3.6 \\
Totals & & $16,150,000$ & $6.9 \%$ & 53.9 \\
Canada & & $30,100,000$ & $4.0 \%$ & - \\
\hline
\end{tabular}

Within those regions, on the other hand, growth in both population and employment has continued to decentralize outward from the older urban cores. The net effect is the emergence of geographically extensive urban regions, at least around those metropolitan areas that are growing. In the larger urban regions development now spreads over thousands of square kilometers. With the continued suburbanization of firms, and the appearance of new exurban concentrations of industrial employment, labour market catchment areas now extend over 100 kilometers from the urbanized core. Yet, suburban growth is not locally dispersed or haphazard. In most regions the new employment agglomerations that are deve- 
loping in newer suburban and exurban regions have simply accelerated the trend toward a poly-nucleated urban form.

Nationally, as a direct consequence of the reorientation of trade flows to international (i.e. US) markets, and the dominance of immigration as a determinant of population growth, the national urban system can be seen as fragmenting into a series of regional subsystems. Some of those subsystems, notably those focused on the larger metropolitan areas, are being drawn into the orbits of much larger, continental or global urban systems, and away from their traditional partners of exchange within the country. Those places not plugged into the continental or global economies, either through trade or immigration, or both, are becoming more detached from the metropolitan areas that dominate the national system. If this divergence of growth trajectories, and the weakening of the ties that underlies it, continue, the consequences for national economic and political integration and identity could be substantial.

\section{NEW URBAN DIFFERENCES}

Returning to the initial proposition, the question is whether the trends outlined briefly above have, on balance, tended to increase the differences among individual urban places with respect to their structural attributes, living conditions, economic vitality and future prospects. Have they replaced, supplanted or added to the traditional sources of differences among cities within the Canadian urban system - for example, those based on contrasts between urban places located in the industrial core and northern periphery, between east and west, between French and English communities, and between types of urban economic base.

Although it is not possible to evaluate the relative importance of all of these sources here with the data and analyses available to date, it is possible to provide examples of both new and extended sources of differences among the country's urban places. These differences are reflected in the following trends:

1. slower population growth overall has produced new sets of winners and losers within the urban system, and widespread urban decline.

2. an increase in the overall variability of growth rates among urban areas.

3. the continued concentration of growth in the largest metropolitan regions while small cities and even small metropolitan areas now show persistent decline.

4. sharper differences among cities in terms of economic viability and economic dependence, and thus enhanced vulnerability to external economic shocks.

5. wider contrasts in the demographic potential of urban places, as mirrored in the rapidly aging populations and older age structures of small and declining communities, that also have future population decline built-in.

6. increased differences in levels of social and cultural diversity, primarily attributable to immigration, with increasing ethno-cultural heterogeneity prevailing in some places (in immigrant reception areas) and persistent homogeneity in most other places. 
7. wider variation in levels of social dependency between those places with aging populations and smaller working age populations, and those with younger and growing populations.

8. diverging levels of personal investment assets (e.g. housing) and in wealth accumulation are evident, due largely to appreciating assets in growing regions and depreciating assets in declining regions.

9. Government policy, in combination with economic and social trends, has produced even wider variations in the fiscal capacity of local and regional governments and in their ability to deliver high-quality goods and services to their residents.

10. in sum, increasing differences in the quality of urban life.

It is evident from our analyses to date that most of the inherited sources of difference among cities have persisted. This is especially the case in the contrasting fortunes of places located in the east of the country and those in Ontario and the west; between resource-based northern communities and those in the settled ecumene; and between French and English communities. Yet new and augmented sources of difference, based on the factors identified above, have been superimposed on, and often replaced, the traditional urban divides. Of these new sources, demographic change, increased trade liberalization and higher levels of immigration, have been the most prominent factors.

These factors, in turn, translate into wider differences in employment opportunities, wealth accumulation, social dependency and municipal fiscal capacity.

Differences between places, of course, can be positive or negative, or sometimes both. And, identifying differences is not the same as explaining their existence or assessing their consequences (Fincher and Jacobs, 1998). Nevertheless, lower rates of population and employment growth, and certainly rapid decline, sets in motion a series of negative multipliers that lower both expectations and opportunities.

\section{CONCLUSIONS}

Cities everywhere are increasingly subject to the effects of external factors over which they have little or not control. But in all instances these forces intersect in complex ways with national and local forces to shape the growth trajectories and attributes of individual cities and entire urban systems. This paper has attempted to illustrate that combinations of global, national and local factors have created new orders of differences among Canadian cities. Often these differences have magnified traditional contrasts among cities in other cases new dimensions of difference have arisen.

Among those factors the discussion in this paper has emphasized four sets of factors: first, the impact of economic restructuring and trade liberalization on urban economies and networks of linkages; second, the increased importance of foreign trade relative to interregional flows; third, demographic change and lower fertility; and fourth, declining domestic migration in combination with higher levels of immigration. Two of these factors - immigration and trade - represent the forces of globalization, but both are also regulated directly 
by policies of the national government. National borders and policies still matter. Cities, on the other hand, have little or no say in either of these policy spheres.

What are the implications of increased levels of difference between urban places? The differences that matter are those that increase or decrease the potential for growth, in employment and income, that increase differentials in level of access to services, and those that augment inequalities in living standards and quality of life. Communities that are small, with declining and aging populations, and with weak and vulnerable economic bases, are likely to be the losers. The winners, in contrast, are likely to be the larger metropolitan regions, with high levels of services, links to the international economy and a population growing through immigration.

These contrasts, if they continue to expand, will ultimately have implications for the viability of the nation state. In particular, wider urban differences will make achieving political consensus more difficult, and will likely further undermine the tacit acceptance of regional transfer payments (equalization), and the broader social contract, that bind the country together.

\section{References}

Beaverstock, J. et al., 2002: Globalization and World Cities. GaWC Research Program, Loughborough University, UK.

Bourne, L.S., 2002: "The Canadian Urban System: Old Structures, Recent Trends and New Challenges", in W.K.D. Davies and I. Townshend (eds.). Monitoring Cities: International Perspectives. Berlin and Calgary: IGU and University of Calgary, pp 15-31.

Bourne, L.S. and Rose, D., 2001: "The Changing Face of Canada: The Uneven Geographies of Population and Social Change", The Canadian Geographer, 45, 1, 105-119.

Bourne, L.S. and Simmons, J. 2002: "The Dynamics of the Canadian Urban System", in M. Geyer (ed.). International Handbook of Urban Systems: Studies of Urbanization and Migration in Advanced and Developing Countries. Cheltenham, UK: E. Elgar, pp. 391-418.

Bourne, L.S. and Simmons, J., 2003: "New Fault Lines?: Recent Trends in the Canadian Urban System and Their Implications for Planning and Public Policy". Canadian Journal of Urban Research, 12, 1, Summer, pp. 1-27.

Bradford, N., 2002: Why Cities Matter. Policy Research Perspectives for Canada. Ottawa: Canadian policy Research Network.

Champion, A. and Hugo, G. eds. 2003: New Forms of Urbanization: Beyond the RuralUrban Dichotomy. Aldershot, UK: Ashgate (forthcoming).

Courchene, T. and Telmer, C., 1998: Ontario: From Heartland to North American Region State. Toronto: University of Toronto Press.

Fincher, R. and Jacobs, J. eds., 1998: Cities of Difference. New York: Guilford Press.

Geyer, H.S. ed. 2002: International Handbook of Urban Systems: Studies of Urbanization and Migration in Advanced and Developing Countries. Northampton MA: E. Elgar Publishing. 
Harris, R. ed. 2003: North American Linkages. Calgary: University of Calgary Press.

Ley, D. and Hiebert, D. 2001: Immigration Policy as Population Policy", The Canadian Geographer, 45, 1, 120-126.

Marcuse, P. and van Kempen, R. eds. 2000: Globalizing Cities: A New Spatial Order?

Oxford: Blackwell.

Polese, M. and Shearmur, R. 2002: The Periphery in the Knowledge Economy. Montreal: INRS.

Simmons, J. and McCann, L. 2000: Growth and Transition in the Canadian Urban System, in P. Filion and T. Bunting, eds. Canadian Cities in Transition. Toronto: Oxford University press, pp. 97-120.

Simmons, J. and Bourne, L.S., 2003: The Canadian Urban System: Responses to a Changing World. Research Paper No. 200, Centre for Urban and Community Studies, University of Toronto, Toronto, Canada. 